\title{
Postoperative nausea and vomiting at a tertiary care hospital in north- western Tanzania
}

PHILLIPO L. CHALYA*, ONESMO Z. MHEWA and JOSEPH B. MABULA

Catholic University of Health and Allied Sciences-Bugando, Mwanza, Tanzania

\begin{abstract}
Background: Postoperative nausea and vomiting is one of the most distressing morbidities associated with surgery. This descriptive prospective study was conducted to determine the incidence, predictors and management of postoperative nausea and vomiting among patients attending a tertiary hospital in northwestern Tanzania.

Methods: The study was conducted in the surgical wards and intensive care unit of Bugando Medical Centre in Mwanza, Tanzania between January 2013 and December 2013. The study population included adult patients aged $\geq 18$ years, classified as ASA I and who were scheduled for elective surgeries under general or region anaesthesia. Patients were assessed preoperatively, intraoperatively and postoperatively. A questionnaire was administered to each patient in order to collect the information on demographic characteristics, estimated patient's body mass index, smoking status, prior history of motion sickness or post-operative nausea and vomiting (PONV), type and duration of surgery/anaesthesia, intraoperative pethidine use, postoperative pain and timing of oral intake.

Results: A total of 348 patients (age $=18-76$ years) were included in the study. The male to female ratio was 1.4: 1. The incidence of postoperative nausea and vomiting was $41.4 \%$. Age group 21-30, female gender, history of PONV, general anaesthesia and intraoperative pethidine were the main predictors of PONV ( $p<$ 0.001). Only forty-five (31.3\%) out of the 144 patients who reported their episodes of PONV received any medications.

Conclusion: The incidence of PONV among surgical patients at Bugando Medical Centre is unacceptably high and the predictors of postoperative nausea and vomiting within 24 hours included being a young adult, female, having history of PONV, been under general anaesthesia and intraoperative pethidine. It is recommended that patients with increased likelihood of developing postoperative nausea and vomiting should be given anti-emetic prophylaxis and other preventive measures.
\end{abstract}

Keywords: Postoperative, nausea, vomiting, incidence, predictors, management, Tanzania

\section{Introduction}

Postoperative nausea and vomiting (PONV) are among the most common adverse effects related to surgery and anaesthesia (Toner et al., 1996; Hilaire, 1999; Van der Bosch et al., 2005). The adverse effects of PONV range from patient-related distress to postoperative morbidity. PONV may contribute to increased costs, increased length of hospital stay, increased perioperative morbidity and prolonged overall recovery (Eberhart et al., 2004; Amponsah, 2007). The overall global incidence of PONV among surgical patients is 25-30\% (Toner et al., 1996; Hilaire, 1999; Kovac, 2000; Kazemi-Kjellberg et al., 2001; Van der Bosch et al., 2005; Gan, 2006) but among highrisk patients it can be as high as 70-80\% (Apfel et al., 1999, 2004; Henzi et al., 2000; Apfel et al., 2002, 2004, 2005; Gan., 2006). Ssebuufu et al. (2009) in Uganda and Amponsah (2007) in Ghana reported the incidence of PONV within 24 hours after surgery to be $40.7 \%$ and 34.6\%, respectively.

It has been suggested that the aetiology of PONV is multifactorial. Several studies have identified several factors that increase the likelihood of PONV (Kovac, 2000; Kazemi-Kjellberg et al., 2001; Maleck \& Piper, 2002; Van der Bosch et al., 2005; Gan, 2006). These factors can generally be categorized into patient, surgical and anaesthetic factors. Apfel et al (1999) identified four predictors of PONV namely the female gender, history of motion sickness or previous PONV, nonsmoking and the use of postoperative opioids.

Despite the vast amount of research done in this field and the variety of antiemetic drugs available, PONV still has a high incidence (Van der Bosch et al., 2005; Smith et al., 2012). Knowledge of the risk factors of PONV can assist the anaesthetist in the judicious use of pharmacotherapy to ameliorate this problem, especially among the high-risk patients (Apfel et al 
1999; Van der Bosch et al., 2005); and may lead to a more cost effective and efficient means of managing PONV (Habib et al., 2006; Ebell., 2007; Smith et al., 2012).

The management of PONV requires a multi-modal approach which include the use of less emetogenic anaesthetic techniques, balanced analgesia, appropriate intravenous hydration, the use of pharmacotherapy and possibly non-pharmacologic methods (Kazemi-Kjellberg et al., 2001; Van der Bosch et al., 2005; Chandrakantan \& Glass, 2011; Holmér-Pettersson \& Wengström, 2012). The thorough understanding of the mechanism of nausea and vomiting and a careful assessment of risk factors provide a rationale for appropriate management of PONV. Strategies that include reductions of the baseline risk and a multimodal approach will most likely ensure success in preventing and treating PONV (Gan, 2006; Smith et al., 2012).

Despite high incidence of PONV reported in literature, no previous work on the condition has been published from north-western Tanzania. This study was carried out to determine the incidence and management of PONV at Bugando Medical Centre and to identify factors that can predict the likelihood of its occurrence.

\section{Materials and Methods}

\section{Study design and setting}

This was a descriptive prospective study which was conducted in the surgical wards and intensive care unit (ICU) of Bugando Medical Centre (BMC) between January 2013 and December 2013. Bugando Medical Centre, one of the four largest referral hospitals in the country. It is located in Mwanza City in the north-western part of Tanzania. It is a 1000 bed, tertiary care and teaching hospital for the Catholic University of Health and Allied Sciences-Bugando (CUHAS).

\section{Study population}

The study population included adult patients aged 18 years and above, classified as ASA I and who were scheduled for elective surgeries under general or regional anaesthesia. Recruitment of patients to participate in the study was done at the Accident and Emergency (A\&E) department, in the operating theatre/ recovery room and in surgical wards. The purpose of the study was explained to the patients and after that a written informed consent was obtained. Patients were assessed preoperatively, intraoperatively and postoperatively. A questionnaire was administered to each patient in order to collect the following information: age, gender, estimated patient's body mass index (BMI), smoking status, prior history of motion sickness or PONV, type of surgery, type and duration of surgery/anaesthesia, intraoperative pethidine use, postoperative pain and timing of oral intake. The type of anaesthesia was classified as general or regional according to the type of surgery and anaesthetist's opinion. The final outcome which was postoperative nausea, postoperative vomiting and postoperative nausea and vomiting was considered dependent (outcome) variable. Other information included episodes and time interval between the end of anaesthesia and PONV and the management.

Patients who were unable to give consent for the study, patients who had nausea or vomiting during the period 24 hours before surgery, patients who had raised intracranial pressure and patients who received an anti-emetic in the period 48 hours before surgery were excluded from the study. Patients who were discharged before 24 hours and those who were operated from other hospitals were also excluded from the study.

PONV was defined as having at least one episode of nausea, vomiting or both within 24 hours postoperatively. Patients were considered nauseated, if they responded to the question "are you or have you felt nauseated since your discharge from recovery room." The study patients were followed up for 48 hours postoperatively. Patients who presented with PONV were managed accordingly. 


\section{Data analysis}

Statistical data analysis was done using SPSS software version 17.0 (SPSS, Inc, Chicago, IL). Data was summarized in form of proportions and frequent tables for categorical variables and median (+Interquartile range (IQR) for continuous variables. Continuous variables were analysed by separating means using Independent Samples t-test. In the univariate analysis, Odds ratio together with $95 \%$ confidence interval was calculated to test for the association between the possible predictors and outcome variables (PONV). Then Pearson Chi-square test was used to test the level of significance. A p-value of less than 0.05 was considered to constitute a statistically significant difference. All variables that were found to be statistically significant on univariate analysis were entered into a multivariate logistic regression analysis to determine prognostic factors of PONV.

\section{Ethical considerations}

Ethical approval to conduct the study was obtained from the CUHAS/BMC joint institutional ethic review committee before the commencement of the study. Patients who met the inclusion criteria were requested to sign a written informed consent before being enrolled into the study.

\section{Results}

\section{Preoperative patient's characteristics}

During the period of study, a total of 348 patients were studied. The age of patients ranged from 18 to 76 years with a median of 28 years (+ IQR of 24 to 30 years). The modal age group was 21-30 years accounting for $49.4 \%$ of patients. Out of 348 patients, $202(58.0 \%)$ were males and 146 (42.0\%) females with the male to female ratio of $1.4: 1$. The majority of patients, $212(60.9 \%)$ had BMI of 20-25 (normal weight). Previous history of PONV and morning sickness was reported among $12.1 \%$ and $24.4 \%$ of patients, respectively. Fifty-four (15.5\%) patients were smokers (Table 1 ).

Table 1: Preoperative patient's characteristics

\begin{tabular}{llll}
\hline Predictor variable & & Number & Percentage \\
\hline Age (years) & $<20$ & 36 & 10.3 \\
& $21-30$ & 172 & 49.4 \\
& $31-40$ & 66 & 19.0 \\
& $41-50$ & 52 & 14.9 \\
Sex & $>50$ & 22 & 6.3 \\
& Male & 202 & 58.0 \\
BMI & Female & 146 & 42.0 \\
& $<20$ (underweight) & 107 & 30.7 \\
& $20-25$ (normal weight) & 212 & 60.9 \\
History of PONV & $26-39$ (overweight) & 21 & 6.0 \\
& $>30$ (obese) & 8 & 2.3 \\
History of motion sickness & Yes & 42 & 12.1 \\
& No & 306 & 87.9 \\
Smoking status & Yes & 85 & 24.4 \\
& No & 263 & 75.6 \\
& Smoker & 54 & 15.5 \\
& Non-smoker & 294 & 84.5 \\
\hline
\end{tabular}

\section{Intraoperative and postoperative characteristics}

General anaesthesia was given in $58.0 \%$ of patients, as compared to $42.0 \%$, who received regional anaesthesia. Anaesthetic drugs given during induction of general anaesthesia included ketamine (30.2\%), thiopentone (58.9\%) and $10.9 \%$ propofol. Intraoperative pethidine was given in $29.9 \%$ of patients. Abdominal surgery was the most frequent surgical procedure performed accounting for $32.5 \%$ of cases. No anti-emetics were used intra-operatively on the study patients. The duration of 
operation ranged from 30 to 160 minutes with a median of 72 minutes (+ IQR of $70-76$ minutes). The majority of patients $(87.9 \%)$ had the duration of operation lasting for more than 60 minutes. According to visual analogy scale, more than fifty percent of patients had been experiencing more pain at the end of 24 hours postoperatively. Most of the study patients (81.0\%) had their first oral intake after 12 hours postoperatively. Only $6(1.7 \%)$ patients took orally in the first 6hours (Table 2 ). Postoperatively all the study patients (100\%) received pethidine.

Table 2: Intraoperative and postoperative characteristics

\begin{tabular}{|c|c|c|c|}
\hline \multicolumn{2}{|c|}{ Predicator variable } & No. of patients & Percentage \\
\hline \multirow[t]{2}{*}{ Type of anaesthesia } & General & 202 & 58.0 \\
\hline & Regional & 146 & 42.0 \\
\hline \multirow[t]{3}{*}{ Induction drug } & Ketamine & 61 & 30.2 \\
\hline & Thiopentone & 119 & 58.9 \\
\hline & Propofol & 22 & 10.9 \\
\hline \multirow[t]{2}{*}{ Intraoperative pethidine use } & Yes & 104 & 29.9 \\
\hline & No & 244 & 70.1 \\
\hline \multirow[t]{5}{*}{ Type of operation } & Abdominal surgery & 113 & 32.5 \\
\hline & Thyroid surgery & 80 & 23.0 \\
\hline & Orthopaedic surgery & 68 & 19.5 \\
\hline & Breast surgery & 61 & 17.5 \\
\hline & Others & 46 & 7.5 \\
\hline \multirow[t]{2}{*}{ Duration of operation (minutes) } & $\leq 60$ & 42 & 12.1 \\
\hline & $>60$ & 306 & 87.9 \\
\hline \multirow[t]{2}{*}{ Post-operative pain } & Less pain & 166 & 47.7 \\
\hline & More pain & 182 & 52.3 \\
\hline \multirow[t]{3}{*}{ Timing of first oral intake (hours) } & $0-6$ & 6 & 1.7 \\
\hline & $7-12$ & 60 & 17.3 \\
\hline & $13-24$ & 282 & 81.0 \\
\hline
\end{tabular}

\section{Incidence and predictors of postoperative nausea and vomiting}

Of the 348 patients, PONV occurred in 144 (41.4\%) of whom 62(43.1\%) had nausea and vomiting, 55 (38.2\%) had nausea only and $27(18.8 \%)$ had vomiting only. According to univariate analysis significant pre-operative factors associated with PONV were age, sex, previous history of PONV, history of motion sickness and smoking status (Table 3). According to univariate analysis, the intra-operative and postoperative factors associated with PONV were general anaesthesia, pestidine use and duration of operation of more than 6ominutes (Table 4).

Table 3: Pre-operative factors associated with PONV according to univariate analysis

\begin{tabular}{|c|c|c|c|c|c|}
\hline \multirow[t]{2}{*}{ Predictor variable } & \multicolumn{2}{|r|}{ PONV } & \multirow[t]{2}{*}{ OR } & \multirow[t]{2}{*}{$95 \% \mathrm{Cl}$} & \multirow[t]{2}{*}{ P-value } \\
\hline & Present (N/\%) & Absent (N/\%) & & & \\
\hline \multicolumn{6}{|l|}{ Age (in years) } \\
\hline$<20$ & $8(22.2)$ & $28(77.8)$ & & & \\
\hline $21-30$ & $80(46.5))$ & $92(53.5)$ & 2.56 & $1.22-6.66$ & 0.023 \\
\hline $31-40$ & $24(36.4)$ & $42(63.6)$ & 3.23 & $0.45-3.98$ & 0.892 \\
\hline $41-50$ & $22(42.3)$ & $30(57.7)$ & 1.09 & $0.93-2.76$ & 0.564 \\
\hline$>50$ & $10(45.5)$ & $12(54 \cdot 5)$ & 1.98 & $0.45-4.43$ & 0.457 \\
\hline \multicolumn{6}{|l|}{ Sex } \\
\hline Male & $42(20.8)$ & $160(79.2)$ & & & \\
\hline Female & $102(69.9)$ & $44(30.1)$ & 4.67 & $1.49-6.89$ & 0.003 \\
\hline \multicolumn{6}{|l|}{ BMI } \\
\hline$<20$ & $38(35.5)$ & $69(64.5)$ & & & \\
\hline $20-25$ & $94(44 \cdot 3)$ & $118(55.7)$ & 1.11 & $0.45-3.49$ & 0.057 \\
\hline $26-30$ & $8(38.1)$ & $13(61.9)$ & 3.22 & $0.98-4.87$ & 0.542 \\
\hline$>30$ & $4(50.0)$ & $4(50.0)$ & 1.43 & $0.56-2.68$ & 0.438 \\
\hline History of PONV & & & & & \\
\hline
\end{tabular}




\begin{tabular}{|c|c|c|c|c|c|}
\hline Yes & $24(57.1)$ & $18(42.9)$ & & & \\
\hline No & $120(39.2)$ & $186(60.8)$ & 0.43 & $0.11-0.98$ & 0.012 \\
\hline \multicolumn{6}{|c|}{$\begin{array}{l}\text { History of motion } \\
\text { sickness }\end{array}$} \\
\hline Yes & $20(23.5)$ & $65(76.5)$ & & & \\
\hline No & $124(47.1)$ & $139(52.9)$ & 0.18 & $0.11-0.98$ & 0.032 \\
\hline \multicolumn{6}{|l|}{ Smoking } \\
\hline Smoker & 18(33.3) & $36(66.7)$ & & & \\
\hline Non-smoker & $126(42.9)$ & $168(57.1)$ & 1.56 & $1.11-5.76$ & 0.011 \\
\hline
\end{tabular}

According to multivariate logistic regression analysis; age group 21-30, female gender, history of PONV, general anaesthesia and intraoperative pethidine were the main predictors of PONV $(\mathrm{p}<$ 0.001) (Table 5).

Table 4: Intra-operative and postoperative factors associated with PONV according to univariate analysis

\begin{tabular}{|c|c|c|c|c|c|}
\hline \multirow[t]{2}{*}{ Predictor variable } & \multicolumn{2}{|c|}{ PONV } & \multirow[t]{2}{*}{ OR } & \multirow[t]{2}{*}{$95 \% \mathrm{Cl}$} & \multirow[t]{2}{*}{ P-value } \\
\hline & Present (N/\%) & Absent (N/\%) & & & \\
\hline \multicolumn{6}{|l|}{ Type of anaesthesia } \\
\hline General & $104(51.5)$ & $98(48.5)$ & & & \\
\hline Regional & $40(27.4)$ & $106(72.6)$ & 3.82 & $1.33-5.11$ & 0.002 \\
\hline \multicolumn{6}{|c|}{ Induction drugs $*(\mathrm{~N}=202)$} \\
\hline \multicolumn{6}{|c|}{ Intraoperative Pethidine use } \\
\hline Yes & $82(78.8)$ & $22(21.2)$ & & & \\
\hline No & $62(25.4)$ & $182(74.6)$ & 1.99 & $1.22-6.92$ & 0.001 \\
\hline \multicolumn{6}{|l|}{ Type of operation } \\
\hline Abdominal surgery & $44(38.9)$ & $69(61.1)$ & & & \\
\hline Thyroid surgery & $32(40.0)$ & $48(60.0)$ & 1.16 & $0.65-3.43$ & 0.717 \\
\hline Orthopaedic surgery & $46(67.6)$ & $22(32.4)$ & 0.43 & $0.11-0.96$ & 0.011 \\
\hline Breast surgery & $18(29.5)$ & $43(70.5)$ & 3.02 & $0.28-4.85$ & 0.882 \\
\hline Others & $4(15.4)$ & $22(84.6)$ & 1.49 & $0.16-2.98$ & 0.418 \\
\hline \multicolumn{6}{|c|}{ Duration of operation (Min) } \\
\hline$\leq 60$ & $24(57.1)$ & $18(42.9)$ & & & \\
\hline$>60$ & $120(39.2)$ & $186(60.8)$ & 0.43 & $0.11-0.98$ & 0.012 \\
\hline \multicolumn{6}{|l|}{ Postoperative pain } \\
\hline Less pain & $68(41.0)$ & $98(59.0)$ & & & \\
\hline More pain & $76(41.8)$ & $106(58.2)$ & 0.33 & $0.13-3.62$ & 0.065 \\
\hline \multicolumn{6}{|c|}{ Timing of $1^{\text {st }}$ oral intake (hrs) } \\
\hline $0-6$ & $2(33.3)$ & $4(66.7)$ & & & \\
\hline $7-12$ & $20(33.3)$ & $40(66.7)$ & 1.45 & $0.69-3.99$ & 0.091 \\
\hline $13-24$ & $122(43.3)$ & $160(56.7)$ & 3.01 & $0.94-4.28$ & 0.876 \\
\hline
\end{tabular}

* This applied only to general anaesthesia

\section{Management of PONV}

In this study, only forty-five (31.3\%) out of the 144 patients who reported their episodes of PONV received any medications. These patients were managed with various anti-emetic drugs (such as promethazine, metoclopramide), anti-malarial drugs and adequate hydration. The majority of the patients were reassured.

\section{Discussion}

In this study, the incidence of PONV was $41.4 \%$, a figure which is comparable with other studies done elsewhere (Toner et al., 1996; Soyannwo et al., 1998; Hilaire, 1999; Khan \& ul Haq, 2000; Van 
der Bosch et al., 2005; Ssebuufu et al., 2009). In agreement with other studies (Soyannwo et al., 1998; Van der Bosch et al., 2005; Ssebuufu et al., 2009), the incidence of PONV was significantly higher in the patients with age group 21-30 years. Age has been reported to be a major predictor of PONV (Sinclair et al., 1999; Apfel et al., 2002). Sinclair et al (1999) in Canada found that age decreased the likelihood of PONV by $13 \%$ for each 10-year increase. The reason for the association between age and PONV is not yet clear.

Table 5: Predictors of PONV according to multivariate logistic regression analysis

\begin{tabular}{llll}
\hline Predictor variable & Odds ratio & $95 \% \mathbf{C l}$ & p-value \\
\hline Age group 21-30 & 3.56 & $1.33-5.98$ & 0.021 \\
Female gender & 1.64 & $1.11-3.81$ & 0.003 \\
History of PONV & 5.93 & $4.23-9.55$ & 0.000 \\
General anaesthesia & 3.98 & $2.32-6.88$ & 0.011 \\
Intraoperative Pethidine & 1.76 & $1.22-9.27$ & 0.032 \\
\hline
\end{tabular}

Like in this study, a number of other investigators have reported a significantly higher incidence of nausea and vomiting after surgery in female patients compared to male patients (Soyannwo et al., 1998; Van der Bosch et al., 2005; Ssebuufu et al., 2009). In the present study, the female gender increased the likelihood of PONV by three times. This finding was in agreement with what has previously been reported from studies done elsewhere (Cohen et al., 1994; Koivuranta et al., 1997; Sinclair et al., 1999; Apfel et al., 2002; Ssebuufu et al., 2009). Soyannwo et al. (1998) in Nigeria found that women had significantly more emetic symptoms than men and suggested that Nigerian women be considered for prophylactic anti-emetic therapy, especially when given narcotic analgesia. This gender difference is attributed to by variation in serum gonadotropin or other hormone levels.

There is positive correction between body weight and PONV (Sinclair et al., 1999; Apfel et al., 2002; Ssebuufu et al., 2009). In this study, BMI was not associated with PONV. Obese patients have been reported as more likely to experience PONV (Hilaire, 1999). Kranke et al. (2001) found no evidence of increased BMI as a risk factor for PONV. This association between increased BMI and PONV may be due to an increased intra-abdominal pressure and the pharmacokinetic effects of lipophilic anaesthetic agents having prolonged half lives in these patients. In this case, adipose tissue acts as a reservoir for inhaled anaesthetic agents, from which they continue to enter the blood stream even after their administration, has been discontinued.

In keeping with other studies (Soyannwo et al., 1998; Sinclair et al., 1999; Apfel et al., 2002; Ssebuufu et al., 2009), a previous history of PONV was also strongly associated with PONV. Also, in this study, patients who had a history of motion sickness were more likely to have PONV than their counter parts that did not have a history of motion sickness, though this was not statistically significant in multivariate logistic regression analysis. This finding is similar to the study done by others (Busone et al., 2002; Ssebuufu et al., 2009). It has been alleged that patients with previous history of PONV or motion sickness may have well developed reflex arc for vomiting (Palazzo \& Strunin, 1984).

In this study, non-smokers were more likely to have PONV than smokers, though this was not statistically significant. The mechanism by which cigarette smoke protects from PONV is not known. Smoking has been reported to be associated with a decreased risk for PONV (Chimbira \& Sweeney, 2000; Whalen et al., 2006). Duncan et al. (1992) reported a relative risk for PONV in smokers as 0.6 while Sinclair et al (1999) reported that smoking decreased the likelihood of PONV by $34 \%$.

Anaesthetic technique has been reported to be a predictor of PONV (Apfel et al., 2005; Drain \& Odom-Forren, 2009; Smith et al., 2012). Compared with regional anaesthesia, general anaesthesia is associated with an 11-fold increase in risk for PONV (Apfel et al., 2005). In our study, patients receiving general anaesthesia experienced two times more incidence of PONV, compared to regional anaesthesia. Similar finding had previously been reported by others 
(Duncan et al., 1992; Apfel et al., 2005; Drain \& Odom-Forren, 2009). Increased incidence of postoperative nausea and vomiting with general anaesthesia could be related to use of volatile anaesthetic with perioperative opioids. General anaesthetic drugs decrease the level of consciousness by decreasing the action potential amplitude and frequency of the central nervous system (Drain \& Odom-Forren, 2009). This disruption of normal neural electrical output can stimulate the chemoreceptor trigger zone (CTZ) and vomiting centre (Apfel et al., 2005).

It has been reported that the use of some anaesthetic drugs are associated with postoperative nausea and vomiting (Drain \& Odom-Forren, 2009; Smith et al., 2012). For instance, thiopentone, etomidate, and ketamine are more emetogenic than propofol (Apfel et al., 2005). The present study showed no association between anaesthetic drugs used and the incidence of PONV. In line with other studies (Apfel et al., 2005; Ssebuufu et al., 2009), intra-operative use of pethidine in this study was found to be statistically significantly associated with PONV. The reason for this is due to the fact that pethidine which is an opioid directly stimulates the CTZ and vestibular apparatus, and also decreases motility of the gut (Resine \& Paternak, 1996).

The effect of the type of surgery on the incidence of PONV has been debated in the literature (Soyannwo et al., 1998; Sinclair et al., 1999; Apfel et al., 2002). Some studies have suggested that the type of surgery is associated with a high incidence of PONV, whereas others have suggested that differences in the incidence of PONV are mainly due to patient- or anaesthesiarelated factors (Apfel et al., 2004). It is unclear if the association is caused by the different anaesthetic agents, the different lengths of operation, or the operation itself (Sinclair et al., 1999; Apfel et al., 2002). In our study, the type of surgery was not significantly associated with PONV which is at variant with Ssebuufu et al (2009) in Uganda who reported an association between orthopaedic operations and PONV. The operative time has been reported to have an effect on the incidence of PONV, with more frequent PONV being reported after longer operations (Apfel et al., 2002; Van den Berg et al., 2005). With increasing duration of surgery and anaesthesia, the risk of PONV increases possibly because of greater accumulation of emetogenic anaesthetic agents (Sinclair et al., 1999; Apfel et al., 2002). However, in this study we observed no association between the duration of operation and the incidence of PONV.

Most studies have reported that postoperative pain is a common cause of PONV (Anderson \& Krohg, 1976; Sinclair et al., 1999; Apfel et al., 2002; White \& Nolan, 2005). This causal relationship is at variant with the present study which reported no association between postoperative pain and PONV. Anderson \& Krohg (1976) found that relief of pain was frequently associated with relief of nausea. This relationship between postoperative pain and vomiting is supported by the increased emesis following naloxane reversal of opiod-mediated pain relief (White \& Nolan, 2005).

The timing of oral intake after surgery can influence the incidence of nausea and vomiting in the postoperative period (Apfel et al., 2002; Van den Berg et al., 2005). Van den Berg et al (2005) have shown that early oral intake after surgery is associated with increased incidence of PONV. This is at variant with Ssebuufu et al. (2009) who reported no association between timing of postoperative oral intake and PONV. Our study also demonstrated no association between timing of postoperative oral intake and PONV.

The small percentage of patients, who received treatment for PONV is a reflection of how health workers view the clinical significance of PONV. This finding is similar to a study done by Amponsah (2007) in Ghana where only about one-tenth of the patients who had PONV received any medication. The management of PONV includes adequate hydration, oxygenation and antiemetics. Various drugs have been used in the management including anticholinergics, antihistamines, phenothiazines, benzamides, butyrophenones and more recently dexamethasone and 5-HT3- receptor antagonists (Kazemi-Kjellberg et al., 2001; Van der Bosch et al., 2005; Apfel et al., 2012; Smith et al., 2012; De Oliveira et al., 2013). In general no drug used for prophylaxis should be re-administered as treatment in the immediate postoperative period. An agent from a different pharmacologic class should be used since the prophylactic drug is deemed 
to have failed. A combination of drugs may be needed in severe cases especially in patients with two or more risk factors (Holmér-Pettersson \& Wengström, 2012; Smith et al., 2012).

In conclusion, the incidence of PONV among surgical patients at Bugando Medical Centre is unacceptably high. The independent predictors of PONV within 24 hours after surgery, following multivariate logistic regression analysis include age group 21-30, female gender, history of PONV, general anaesthesia and intraoperative pethidine. It is recommended that patients with increased likelihood of developing postoperative nausea and vomiting should be given anti-emetic prophylaxis.

\section{Acknowledgements}

The authors would like to acknowledge all those who participated in the preparation of this manuscript, and those who were involved in the care of our patients.

\section{References}

Amponsah, G. (2007) Postoperative nausea and vomiting in children in Korle Bu Teaching Hospital. Ghana Medical Journal 41, 181-185.

Apfel, C.C., Roewer, N. \& Korttila, K. (2002) How to study postoperative nausea and vomiting. Acta Anaesthesiologica Scandinavica 46, 921-928.

Apfel, C.C., Stoecklein, K. \& Lipfert, P. (2005) Postoperative nausea and vomiting: a problem of inhalational anesthesia? Best Practice \& Research Clinical Anesthesiology 19, 485-500.

Apfel, C.C., Korttila, K., Abdalla, M., Kerger, H., Turan, A., Vedder, I., Kredel M, Biedler, A, Sessler, D.I., Roewer, N., IMPACT Investigators (2004) A factorial trial of six interventions for the prevention of postoperative nausea and vomiting. New England Journal of Medicine 350, 2441-2451.

Apfel, C.C., Meyer, A., Orhan-Sungur, M., Jalota, L., Whelan, R.P. \& Jukar-Rao, S. (2012) Supplemental intravenous crystalloids for the prevention of postoperative nausea and vomiting: quantitative review. British Journal of Anaesthesia 108, 893-902.

Chandrakantan, A. \& Glass P.S. (2011) Multimodal therapies for postoperative nausea and vomiting, and pain. British Journal of Anaesthesia 107, 27-40

Chimbira, W. \& Sweeney, B.F. (2000) The effect of smoking on postoperative nausea and vomiting. Journal of Association of Anaesthetists of Great Britain and Ireland 55, 540.

Cohen, M.M., Duncan, P.G., DeBoer, D.P. \& Tweed, W.A. (1994) The postoperative interview: assessing risk factors for nausea and vomiting. Anesthesia and Analgesia 78, 7-16

De Oliveira, G.S. Jr, Castro-Alves, L.J., Ahmad, S., Kendall, M.C. \& McCarthy, R.J. (2013) Dexamethasone to prevent postoperative nausea and vomiting: an updated meta-analysis of randomized controlled trials. Anesthesia and Analgesia, 116, 58-74

Duncan, P.G., Cohen, M.M., Tweed, W.A., Biehl, D., Pope, W.D., Merchant, R.N. \& DeBoer, D. (1992) The Canadian four-centre study of anaesthetic outcomes: III. Are anaesthetic complications predictable in day surgical practice? Canadian Journal of Anaesthesia 39, 440448.

Drain, C.B. \& Odom-Forren, J. (2009) Perianesthesia Nursing: A Critical Care Approach. 5th edn. St Louis, MO: Saunders Elsevier

Ebell, M.H. (2007) Predicting postoperative nausea and vomiting. American Family Physician 15, 1537-1538.

Eberhart, L.H., Morin, A.M., Guber, D., Kretz, F.J., Schäuffelen, A., Treiber, H., Wulf, H. \& Geldner G. (2004) Applicability of risk scores for postoperative nausea and vomiting in adults to paediatric patients. British Journal of Anesthesia 93, 386-392.

Gan, T.J. (2006) Risk factors for postoperative nausea and vomiting. Anesthesia and Analgesia 102, 1884-1898. 
Habib, A.S., Chen, Y., Taguchi, A, Hu, X.H. \& Gan, T.J. (2006) Postoperative nausea and vomiting following inpatient surgeries in a teaching hospital: A retrospective database analysis. Current Medical Research and Opinion 22, 1093-1099.

Henzi, I., Walder, B. \& Tramer, M.R. (2000) Dexamethazone for the prevention of postoperative nausea and vomiting: a quantitative systematic review. Anesthesia and Analgesia 90, 186194.

Hilaire, J.T. (1999) The management of postoperative nausea and vomiting. Journal of Advanced Nursing 5, 1130-1136.

Holmér-Pettersson, P. \& Wengström, Y. (2012) Acupuncture prior to surgery to minimize postoperative nausea and vomiting: a systematic review. Journal of Clinical Nursing 21, $1799-805$.

Kazemi-Kjellberg, F., Henzi, I. \& Tramer, M.R. (2001) Treatment of established postoperative nausea and vomiting: a quantitative systematic review. BMC Anesthesiology 1, 2.

Khan, F.A. \& ul Haq, A. (2000) Effect of cricoid pressure on the incidence of nausea and vomiting in the immediate postoperative period. Anaesthesia 55, 63.

Kovac, A.L. (2000) Prevention and treatment of postoperative nausea and vomiting. Drugs 59, 213-243.

Koivuranta, M., Laara, E., Snare, L. \& Alahuhta, S. (1997) A survey of postoperative nausea and vomiting. Anaesthesia 52, 443-449.

Kranke, P., Apfel, C.C. \& Papenfuss T. (2001) An increased body mass index is no risk factor for postoperative nausea and vomiting. Acta Anaesthesiologica Scandinavica 45, 160.

Maleck, W.H. \& Piper, S.N. (2002) Predictive models for postoperative nausea and vomiting. British Journal of Anaesthesia 88, 339-342.

Palazzo, M.G. \& Strunin, L. (1884) Anaesthesia and emesis. I: Etiology. Canadian Journal of Anaestheologists Society 31, 178-187.

Resine, T. \& Paternak, G. (1996) Opioids analgesics and antagonists. In: Hardman, J.G., Limbird, L.E., eds. Goodman and Gilman's The Pharmacological Basis of Therapeutics. New York: McGraw-Hill, 521-555.

Sinclair, D.R., Chung, F. \& Mezei, G. (1999) Can postoperative nausea and vomiting be predicted? Anesthesiology 99, 109-118.

Smith, H.S., Smith, E.J. \& Smith, B.R. (2012) Postoperative nausea and vomiting. Annals of Palliative Medicine 1, 94-102.

Soyannwo, O.A., Ajuwon, A.J., Amanor-Boadu, S.D. \& Ajao, O.G. (1998) Postoperative nausea and vomiting in Nigerians. East African Medical Journal 75, 243-245

Ssebuufu, R., Kakande, I., Okello, M. (2009) Post-operative nausea and vomiting at Mulago Hospital. East and Central African Journal of Surgery 14, 50-57.

Toner, C.C., Broomhead, C.J., LittleJohn, I.J., Samra, I.H., Powney, J.G. \& Palazo, G.A. (1996) Prediction of postoperative nausea and vomiting using a logistic regression model. British Journal of Anesthesia 76, 347-351.

Van den Bosch, J.E., Kalkman, C.J, Vergouwe, Y., Van Klei, W.A., Bonsel, G.J., Grobbee, D.E. \& Moons, K.G. (2005) Assessing the applicability of the scoring system for predicting postoperative nausea and vomitting. Anaesthesia 60, 323-331.

Whalen, F., Sprung, J., Burkle, C., Schroeder, D.R. \& Warner, D. (2006) Recent smoking behaviour and postoperative nausea and vomiting. Anesthesia and analgesia 103, 70-75.

White, M.C., Nolan, J.A. (2005) An evaluation of pain and postoperative nausea and vomiting following the introduction of guidelines for tonsillectomy. Paediatric Anaesthesia 15, 683688. 